\title{
La responsabilidad penal médica en Cuba. Iter histórico, problemas y soluciones
}

\section{The Medical Criminal Liability in Cuba. History, Deficiencies and Solutions.}

Liuver Camilo Momblanc*

DOI: http://dx.doi.org/10.21503/lex.v16i21.1550

* Licenciado en Derecho. Licenciado en Contabilidad y Finanzas. Especialista en Derecho Penal. Especialista en Administración Pública. Profesor auxiliar del Departamento de Calidad. Universidad de Oriente. Santiago de Cuba.

Correo electrónico: liuverc@uo.edu.cu

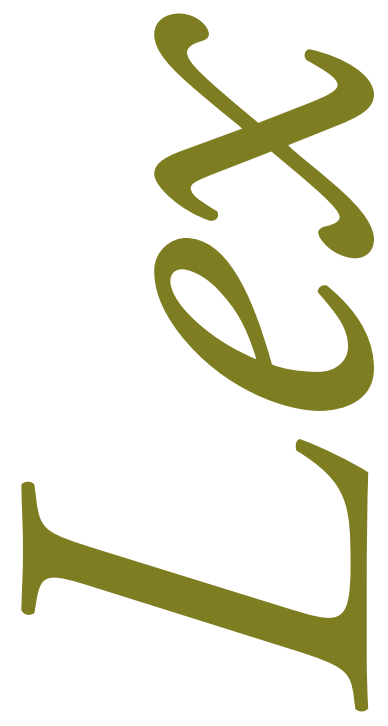

(c) (C) (C) Los autores. Artículo publicado por la Revista Lex de la Facultad de Derecho y Ciencias Políticas de la Universidad Alas Peruanas. Este es un artículo de acceso abierto, distribuido bajo los términos de la Licencia Creative Commons Atribución-No 


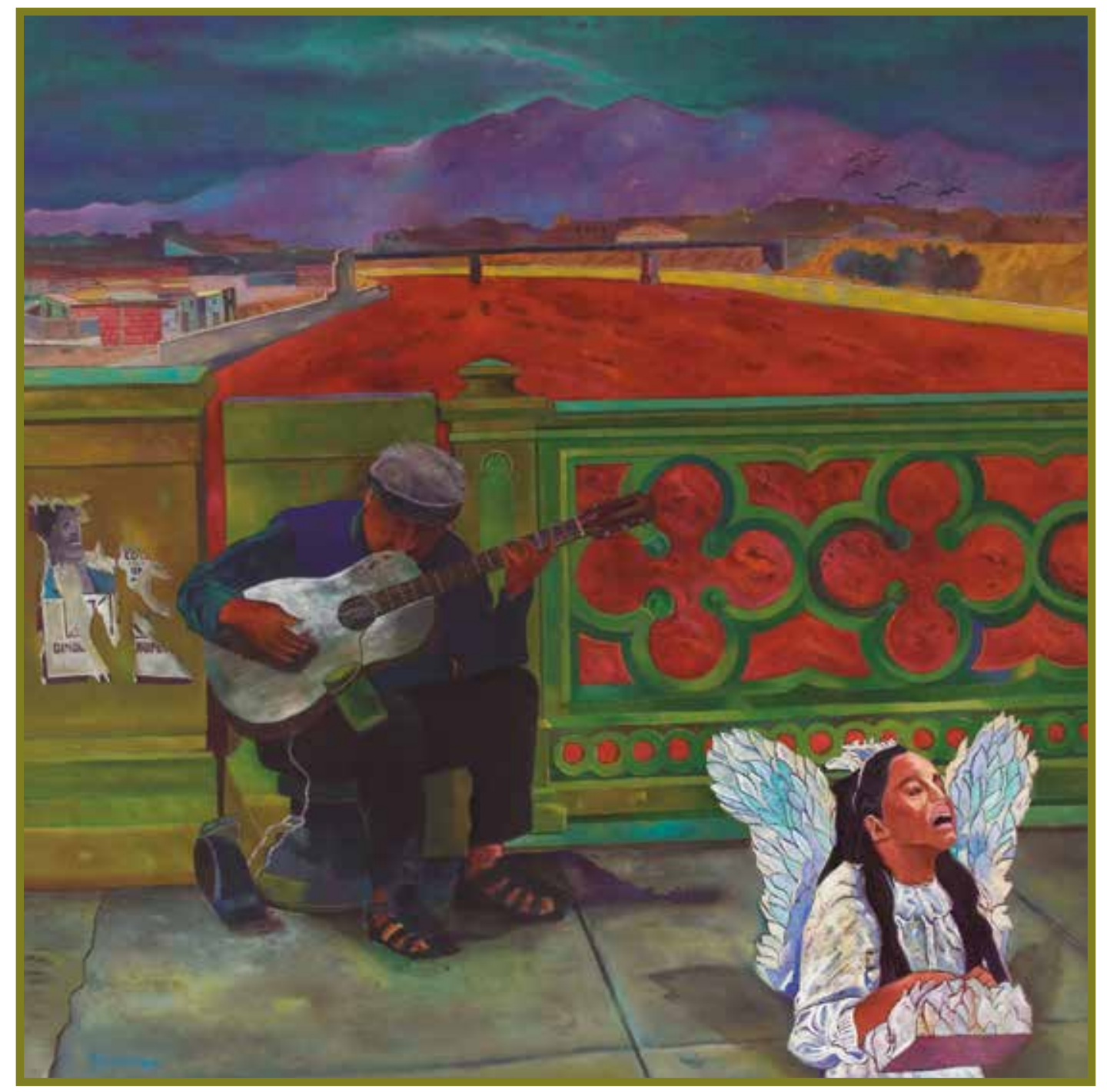

Músico y ángel. Enrique Polanco.

https://www.facebook.com/enriquepolancopintor/ 


\section{RESUMEN}

En el artículo se realiza un análisis histórico-jurídico que permite conocer cómo se ha regulado a lo largo de la historia la responsabilidad penal médica en el ordenamiento jurídico cubano. Esto posibilita una mejor comprensión del procedimiento seguido actualmente en Cuba para la evaluación de la responsabilidad penal en la que pueden incurrir estos profesionales por mala praxis. Se destacan sus deficiencias y proponen bases jurídicas para su perfeccionamiento, de modo que se asegure una mejor evaluación de este tema sin perder de vista ambos extremos de la relación médico-paciente.

Palabras clave: responsabilidad penal, mala praxis, imprudencia médica.

\section{ABSTRACT}

This paper made a legal-historical analysis about the regulations of the medical criminal liability in the history of the Cuban legal system, with the purpose of achieving a better understanding of the current procedure in Cuba for the evaluation of criminal liability of these professionals in cases of malpractice. Are highlighted many deficiencies as well as legal bases were proposed for the improvement of this procedure to ensure a better evaluation of this subject considering the both sides of the doctor-patient relationship.

Key words: criminal liability, malpractice, medical negligence. 


\section{INTRODUCCIÓN}

En la sociedad actual, caracterizada por el desarrollo científico-técnico, los avances en estas esferas se fusionan para entregar sus frutos más recientes que ofrecen mayores oportunidades en cuestiones tan importantes como la salud. Sin embargo, la tecnología por sí sola no basta para evitar el deterioro de este bien e incluso la pérdida de la vida humana. Es cierto que hoy existen más posibilidades de salvar vidas en situaciones complejas que años atrás, cuando no hubiese sido posible ni siquiera un diagnóstico acertado. Pero no todo depende de la tecnología: resulta necesaria la pericia de los profesionales de la salud como principales actores de tan altruista labor. Sin ella, la tecnología sería tan útil como un fusil en manos de un soldado inexperto o tan segura como un arma en manos de un niño.

La medicina es una actividad de seres humanos en seres humanos, en la cual uno, denominado paciente, pone su confianza, esperanzas y organismo en manos de otro llamado médico, cuya misión será curar una enfermedad, salvar su vida. Pero siempre habrá la posibilidad de que en el tratamiento surja un contratiempo, una complicación, un fracaso o resultado adverso, porque el acto médico es en sí mismo potencialmente inseguro al no ser esta una ciencia exacta. En ocasiones, el facultativo, como cualquier otro profesional, puede errar aun empleando todo su conocimiento y medios técnicos a su alcance. $Y$ en estos casos la medicina solo puede "certificar" que lo realizado médicamente responde a las pautas y normas de la lex artis. Por ello, el ejercicio de la medicina es una de las profesiones pletórica de reglas, protocolos, normas jurídicas en constante actualización y de las que más se relaciona con el derecho.

En consecuencia, alrededor de la relación médico-paciente se generan determinados nudos gordianos que exigen, tanto a médicos como juristas, un pensamiento concienzudo para su solución. ¿Cómo garantizarle al paciente el máximo estándar de atención a su salud sin requerir de los médicos conductas heroicas o científicamente imposibles? ¿Cómo asegurarle al médico que la incertidumbre propia de su acto asistencial no se trasladará al cuestionamiento de su integridad y experticia? 
Como se aprecia, el tema de la responsabilidad médica reviste gran importancia en la actualidad, pero cualquier investigación y propuesta debe realizarse sin perder de vista ambos extremos de la relación médico-paciente. Significa que deben protegerse con el mismo cuidado y garantías los sujetos de esta relación. Una posición diferente solo favorecería un desequilibrio perjudicial para todos. Y un aumento de las quejas asociadas a los servicios médicos no bien tramitadas puede originar la existencia de una medicina defensiva ${ }^{1}$ ante el temor de los profesionales de la salud de que sus actuaciones sean continuamente cuestionadas.

\section{LA RESPONSABILIDAD PENAL MÉDICA EN CUBA: ITER HISTÓRICO}

El vertiginoso avance de los conocimientos médicos, así como el perfeccionamiento de la ciencia jurídica han marchado y continúan haciéndolo aparejados al progreso de la humanidad. Dentro del proceso de evolución histórico-social, en la medida en que el desarrollo científico-técnico y su aplicación en la medicina se van ampliando, en esa misma proporción las relaciones sociales en el sector de la salud se han ido tornando cada vez más complejas. Como consecuencia, se producen conflictos en el marco de la relación médico-paciente que el derecho debe solucionar, entre los que destaca el reto que para los órganos judiciales significa, hoy en una mayor proporción, el análisis de la responsabilidad penal en la que puede incurrir un facultativo.

Es por ello que para una mejor comprensión de cómo se ha previsto en Cuba la responsabilidad penal médica, se ilustra su trayectoria histórica normativa a partir de su regulación en los códigos penales promulgados en la Isla. Pero antes de enmarcar el estudio en el escenario cubano, se considera oportuno hacer referencia a algunos aspectos de la historia universal que forman parte del nacimiento y fundamento de la responsabilidad penal médica.

En la antigüedad, el desconocimiento y las fuertes costumbres religiosas imperantes conllevaron a la búsqueda de justificaciones divinizadas para todo aquello que resultaba incomprendido. De ahí que las causas de las enfermedades, así como muchos otros fenómenos naturales y/o sociales se asociaban a decisiones o castigos divinos. El sacerdote en aquel entonces era quien realizaba las labores del médico, lo que justificaba que, existiendo o no mala praxis, no se le aplicara sanción alguna por ser considerados como emisario de Dios en la tierra. ${ }^{2} \mathrm{Al}$ ser relevados por los médicos en la misión de curar enfermedades, también estos fueron con-

1 La medicina defensiva es "aquella que el médico o grupo de médicos desarrollan por el miedo a cometer un error diagnóstico, y que se caracteriza básicamente, por un retraso en la aplicación de un tratamiento, por la solicitud de pruebas e interconsultas con otros compañeros de forma serial y exagerada". Guillermo Portero Lazcano, "Responsabilidad penal culposa del médico: fundamentos para el establecimiento de la negligencia o impericia”, Revista Latinoamericana de Derecho Médico y Medicina Legal 7, 1, (2002): 90.

2 T. E Tapia y V. X. Tapia, "La mala praxis médica, encuadre y consecuencias en el derecho penal y derecho civil" (tesis de grado, Universidad Técnica de Cotopaxi en convenio con la Universidad de la Cuenca del Plata, Corrientes, Argentina, 2010). 
siderados como una especie de seres divinizados a quienes confiar la salud y la vida. Pero con los avances de las ciencias médicas las explicaciones sobrenaturales fueron desplazadas por el conocimiento y comienza a configurarse una postura social enfocada hacia la exigibilidad de responsabilidad a los galenos.

Desde la antigua Mesopotamia, con el Código de Hammurabi, se tienen las primeras evidencias normativas de la exigencia de responsabilidad al médico por las faltas cometidas en su ejercicio profesional. En este histórico instrumento legal se establecían severísimas sanciones por tales faltas. Así, por ejemplo, la ley 218 decretaba que "Si un médico hace incisión profunda en un hombre con bisturí de bronce y le provoca la muerte, o si le abre la sien a un hombre con bisturí de bronce y deja tuerto al hombre, que le corten la mano". ${ }^{3}$

Al mismo tiempo, los egipcios también realizaron grandes aportes a las ciencias médicas, aunque en un primer momento la medicina también fue ejercida por sacerdotes y algunos sanadores. Pero cuando los avances comenzaron a ser más evidentes, se inició una etapa en el desarrollo de la especialización de la medicina y surgieron médicos laicos especializados en distintas dolencias. Ese mayor nivel científico trajo aparejado un incremento de las obligaciones y responsabilidades de los médicos, hasta el punto de que los egipcios llegaron a establecer la pena de muerte a aquel que en el ejercicio de sus labores cometiere alguna falta en la vida de sus semejantes. ${ }^{4}$

Con el desarrollo del pensamiento de grandes filósofos como Platón y Aristóteles se impregna un mayor grado de raciocinio a la exigencia de responsabilidad derivada del proceder médico. Estos desvinculan un poco la medicina de lo religioso y defendieron una relación más estrecha entre la responsabilidad del médico con las características del hecho y del agente comisor. ${ }^{5}$ Todo ello condujo a que durante el Imperio romano afloraran normas relativas a la responsabilidad del médico por conductas negligentes que causan daño en el paciente. Uno de los ejemplos más clásicos lo constituye el Corpus Iuris Civilis de Justiniano, fuente principal del conocimiento del derecho romano, ${ }^{6}$ que tuvo gran influencia en el derecho de los siguientes siglos en todo el mundo.

Parte de la génesis del escenario jurídico normativo cubano está sustentado en la jurisprudencia romana debido a la influencia de esta en el derecho desarrollado con posterioridad en España que se importa a Cuba con la colonización. En consecuencia, el escudrińamiento del

\footnotetext{
Cf. Joaquín Sanmartín, traductor, Códigos legales de tradición babilónica (Barcelona: Trotta, 1999).

Carmen Navarro Odio, "La responsabilidad jurídica penal del médico en Cuba" (tesis de grado, Universidad de Oriente, Santiago de Cuba, 2014), 27.

5 Carmen Navarro Odio, "La responsabilidad jurídica penal del médico en Cuba".

6 En el (...) se agrupan las soluciones jurídicas romanas más importantes, al extremo que fuera del Corpus hay pocas fuentes que agreguen nuevo saber sobre el derecho romano. Julio Fernández Bulté, Teoría del Estado y del derecho. Teoría del derecho (La Habana: Editorial Félix Varela, 2011), 40.
} 
entorno legislativo cubano en aras de identificar las figuras de delito que caracterizan la mala praxis médica o al menos conciban al médico como sujeto activo especial, se inicia con el estudio del Código Penal español de 1870 puesto en vigor en Cuba por Real Decreto de 23 de mayo de 1879.

Según las referencias encontradas, se plantea que esta legislación contenía distintas figuras delictivas relacionadas con la responsabilidad penal del médico como sujetos activos de delitos, generalmente de carácter intencional. En esta dirección, al decir de Parets, el Código recogía en sus artículos 319, 426 y 480 las figuras de expedición falsa de certificado de enfermedad o lesión, aborto ilícito y suposición de parto o sustitución de un niño por otro. ${ }^{7}$ Sin embargo, desde su sola denominación es posible conjeturar que ninguna de estas conductas médicas constitutivas de delito resulta similar a lo que se ha considerado como mala praxis médica. Esta legislación siguió el modelo del Código Penal francés de 1810, expresión de los principios enarbolados por la llamada Escuela Clásica. No existía aún en el escenario social un desarrollo de las concepciones de la bioética médica y mucho menos los nuevos modelos de la relación médico-paciente. ${ }^{8}$ Para entonces, primaba el modelo tradicional paternalista, ${ }^{9}$ razón por la cual no resulta extrańo que no encontremos preceptos reguladores de la mala praxis médica en este Código a pesar de recoger las citadas figuras de delito.

Durante las guerras de independencia, se aprobaron varios textos legales, y en el ámbito penal se sanciona por el Consejo de Gobierno del Poder Revolucionario de Cuba en Armas,

7 Jesús Parets Gómez, "La responsabilidad penal del médico", Revista Cubana de Derecho 2, (1991): 84-85, acceso el 16 de enero de 2016, http://vlex.com/vid/responsabilidad-penal-medico-45042501

8 El nuevo modelo de la relación médico-paciente ha permitido el surgimiento de una variedad de pacientes críticos, desconfiados y beligerantes, posiblemente en respuesta a insatisfacciones propias o de allegados. Es reconocedor y respetuoso de los derechos del paciente, permite segundas y hasta terceras consultas u opiniones antes de decidir. Consultan bases de datos para ver si lo que les indicaron es correcto y cuestionan. Demandan cuando se sienten dańados. En fin, se caracterizan por basarse en una relación de tipo contractual de la relación médico-paciente o prestador de salud usuario; ambas partes con sus derechos y obligaciones, aparición y aumento de reclamos por fallas a las obligaciones. Guido Berro Rovira, "La relación médico-paciente (RMP) y su actual encuadre legal", Revista Biomedicina (2009): 19, acceso el 8 de agosto de 2017, https://www.google.com.cu/url?sa=t\&rct=j\&q=\&esrc=s\&source=web\&cd=2\&ved=0ahUKEwjs2Mzvl8jVAhWJbiYKHYdtBJMQFggvMAE\&url=https\%3A\%2F\%2Fwww.researchgate.net\%2Fpublication\%2F45523004_La_relacion_medico-paciente_RMP_y_su_actual_encuadre_legal\&usg=AFQjCNGO-Hx0bYAFidj1rwkp48sNrUORWQ

9 El juramento hipocrático selló el carácter paternalista de la relación médico-paciente. Los médicos que estudiaron y ejercieron la medicina junto al padre de esa ciencia (Hipócrates) debían cumplir con el juramento de no hacerle daño a sus pacientes. Por ello se afirma que de ahí proviene el principio bioético de no maleficencia. La escuela hipocrática se desarrolla en un clima de gran respeto por la profesión médica, por lo que defiende un modelo de trato con el enfermo en el que lo principal es el bien del paciente: "Prescribiré la dieta oportuna que convenga a cada enfermo", "no daré jamás medicamentos mortales ni cometeré jamás acciones de este género", "estaré atento solamente a la salud de los enfermos". El modelo propuesto en esta tradición, denominado "beneficente-paternalista", ha definido durante muchos siglos la relación médico-paciente. Bajo su concepción, el médico hace el bien al paciente como lo hace un padre a su pequeño hijo. La persona enferma desconoce o conoce mal su enfermedad, su causa y el modo de curarse. El médico posee el saber, sabe lo que le pasa al paciente y le trata de curar, sin que sea necesaria la intervención del propio paciente y con un principio ético básico: "Primum non nocere", "ante todo no perjudicar, no hacer daño". 
con fecha 28 de julio de 1896, la llamada Ley Penal de Cuba en Armas. En ella tampoco encontramos en ninguno de sus artículos referencias a la mala praxis médica. Más tarde, con la intervención norteamericana en 1898, no se deroga el Código Penal español ${ }^{10}$ quedando inamovible la situación hasta ahora descrita. Este escenario tampoco se altera con la aprobación de la Constitución de 1901, que en su Disposición Transitoria Séptima dispuso: “Todas las leyes, decretos, reglamentos, órdenes y demás disposiciones que estuvieren en vigor al promulgarse esta Constitución, continuarán observándose en cuanto no se opongan a ella, mientras no fueran legalmente derogadas o modificadas".

Durante ese período de seudorrepública, distinguidos juristas cubanos propusieron algunos proyectos de códigos penales en aras de conferir al país una legislación autóctona. ${ }^{11}$ Pero ninguno de ellos llegó a tener vigencia y siguió rigiendo el Código Penal español de 1870 extensivo a Cuba en el año 1879 con algunas reformas que procuraron ajustarlo a nuestra realidad. Situación que se mantuvo hasta 1938 cuando se pone en vigor el Código de Defensa Social cubano (CDS). ${ }^{12}$ En él se amplió el campo de la responsabilidad penal de los médicos al ser adicionados dos nuevos tipos penales. En uno de ellos se sancionaba a los facultativos que no dieran parte a la autoridad inmediatamente, cuando al asistir a una persona detectaran signos de haberse cometido un delito. En el otro se describía como ilegal la denegación de auxilio por parte del médico. ${ }^{13}$ Pero no se concibe ningún tipo penal específico para la sanción de la mala praxis médica.

El CDS permaneció vigente al producirse el triunfo revolucionario en 1959, pero fueron tan amplias las reformas que se le hicieron en aras de ajustarlo a las circunstancias de la nueva sociedad que terminó afectado en su sistemática interna, aunque en relación a la institución objeto de estudio no se realizaron cambios. Así, una vez que existieron todas las condiciones culturales, políticas y económicas para la promulgación de un nuevo Código Penal que fuera

10 Así quedó establecido mediante Proclama del Gobernador Militar del 1 de enero de 1889, donde se reguló que: "quedarán en fuerza el Código Civil y el Criminal existentes antes de finalizar la soberanía española, modificándose estos de tiempo en tiempo, cuando sea necesario para el mejor gobierno. Disposición esta que posteriormente se ratifica por la Orden 148 de 1902. Cf. Ramón Yordanis Alarcón Borges, "Las normas penales en blanco en el ordenamiento jurídico penal cubano (tesis presentada en opción al grado científico de Dr. en Ciencias Jurídicas, Universidad de Oriente, Santiago de Cuba, 2011), 100.

11 Fueron cinco los proyectos de Código que por demás sentaron las bases fundamentales para la aparición en 1936 de una legislación penal por primera vez elaborada en Cuba. Estos son: Proyecto de Lanuza (1908-1910), Proyecto de Moisés A. Vietes (1922-1928), Proyecto de Ortiz (1926), Proyecto de Francisco Fernández Plá (1930) y de Diego Vicente Tejera (1932-1936). Cf. Ulises Baquero Vernier, Derecho penal general (Santiago de Cuba: ENSPES, 1984), 14-20.

12 El Código de Defensa Social promulgado por el Decreto-Ley No. 802 del 4 de abril de 1936 y publicado en la Gaceta Ofcial de la República de Cuba, Extraordinaria No. 108 del 11 de abril de 1936, en su Disposición Suplementaria Primera dispuso que comenzaría a regir a los 180 días de su publicación, pero por Ley de 7 de octubre de 1936, publicada en la Gaceta Oficial Extraordinaria de la propia fecha, se suspendió su vigencia por dos años, para entrar en vigor este Código, el 8 de octubre de 1938.

13 Cf. Artículos 299-B y 407-A) del Código de Defensa Social. 
expresión y reflejo de las nuevas relaciones socialistas, se aprobó en 1979 la Ley No. 21. Esta fue el resultado de diez años de intenso trabajo que inició en 1968 una subcomisión y la Comisión de Estudios Jurídicos del Comité Central del Partido Comunista de Cuba, en la que participaron especialistas de las diversas ramas de la actividad jurídica, incluyendo la docente.

En relación a la responsabilidad médica, a pesar de que suprimió la figura de la suposición de parto y de sustitución de un niño por otro, prevista en los anteriores códigos, dio muestra de que se continuaba ensanchando la concepción penal que se había tenido hasta el momento. No solo se amplía la redacción en alguno de los casos de las conductas delictivas ya previstas en las legislaciones precedentes, sino que se continuaron sumando nuevos tipos penales para otras conductas médicas constitutivas de delitos. Y es comprensible que esto ocurriera por cuanto ya se hablaba con fuerza de la bioética médica y habían acontecido grandes casos en el escenario internacional en los que fue exigida responsabilidad a los médicos. ${ }^{14}$

La Ley 21, Código Penal de 1979, si bien superó a sus precedentes, coincidiendo con Medina:

(...) muy pronto se vio superado por la realidad social. La tipificación como delitos de un alto número de figuras de escasa peligrosidad social (...) y la existencia en sus regulaciones de la Parte Especial de marcos sancionadores muy cerrados, con límites mínimos de las sanciones de numerosos delitos muy elevados (...) entre otros aspectos, así como el hecho de que fuera aprobado diez años después del inicio de su redacción, que lo hicieron envejecer antes de su nacimiento, hicieron aconsejable someter el Código Penal a una transformación de tal naturaleza, que finalmente motivó que se adoptara con acierto la decisión de sustituirlo por uno nuevo. ${ }^{15}$

El 30 de abril de 1988 comenzó a regir un nuevo Código Penal en vigor hasta la actualidad, la Ley No. 62. Este Código fue objeto de modificación por los Decretos Leyes 140/93, 150/94 y 175/97, la Ley 87 de 1999, la Ley 93 de 2001 y el Decreto-Ley 310 de 2013, pero en ninguna de estas oportunidades se ha establecido una figura autónoma para la tipificación de la mala praxis médica. Esto no significa la inexistencia de respuesta penal a aquellas conductas médicas que por imprudencia, impericia o negligencia ocasionen la muerte o lesiones de una persona. Hasta aquí solo se ha hecho referencia a figuras delictivas que en su configuración tienen dos denominadores comunes: 1 ) requieren del médico, facultativo o profesional de la medicina como sujeto activo especial y 2) el sujeto activo especial tiene la intenciona-

14 Así, por ejemplo, el Código de Núremberg ya había sido publicado el 20 de agosto de 1947 como producto del conocido juicio de Núremberg, en el, que además de quienes conformaban el régimen político y militar nazi, también fueron juzgados y condenados varios médicos pertenecientes al régimen por desarrollar investigaciones y experimentos que desconocieron y atropellaron los derechos humanos de los sujetos de investigación.

15 Arnel Medina Cuenca, "Comentarios a la Ley No. 62 de 29 de septiembre de 1987: Código Penal", en Derecho Penal Especial. Tomo 3. Colectivos de autores (La Habana: Editorial Feliz Varela, 2003), 56. 
lidad de cometer el hecho punible. Pero en el vigente Código Penal como en los anteriores existen otras figuras delictivas que no requieren de un sujeto activo específico y pueden ser imputadas a los galenos por acciones realizadas en el ejercicio de su profesión. Entre ellas destacan los delitos relativos a la vida e integridad física a los que eventualmente pudiera dar paso el ejercicio de su actividad, específicamente los delitos de lesiones u homicidio.

El delito de homicidio se encuentra regulado en el artículo $261^{16}$ del Código Penal. En este se establece sanción de privación de libertad de 7 a 15 años para aquella persona que cause la muerte a otra. Por su parte, el delito de lesiones ${ }^{17}$ aparece normado en los artículos 272 al 274 del Código Penal y según la gravedad de la lesión se impone pena de privación de libertad de 2 a 5 años en las graves, aumentando el límite máximo del marco sancionador a 12 años en el caso de que a consecuencia de la lesión se provoque ceguera, castración o inutilización para la procreación, y se disminuye la pena pudiendo llegar a imponerse solo multa en las no graves. Pero en los casos en que las lesiones y el homicidio sean resultado de conductas imprudentes, seguidas por el médico o personal auxiliar durante el ejercicio de su profesión, la exigencia de responsabilidad penal se torna más compleja. En estos casos nos encontramos entonces ante un supuesto de los calificados en la doctrina como imprudencia profesional.

En nuestra ley penal sustantiva el delito culposo se halla regulado en el artículo 9.3 con la denominación de "imprudencia". En este se expone que el delito se comete por imprudencia cuando el agente previó la posibilidad de que se produjeran las consecuencias socialmente peligrosas de su acción u omisión, pero esperaba, con ligereza, evitarlas, o cuando no previó la posibilidad de que se produjeran a pesar de que pudo y debió haberlas previsto. Como se advierte, en el Código Penal cubano no se explicita la negligencia, impericia y la infracción de los reglamentos como formas de responsabilidad penal culposa y tampoco se tipifica la mala praxis médica como un tipo penal autónomo. Los hechos de lesiones y homicidio cometidos por el médico o personal auxiliar de manera imprudente durante el ejercicio de su profesión han de resolverse en base a lo estipulado en los citados artículos 261 y 272 al

16 Artículo 261: El que mate a otro incurre en sanción de privación de libertad de siete a quince años.

17 Artículo 272.1: El que cause lesiones graves o dañe gravemente la salud a otro, incurre en sanción de privación de libertad de dos a cinco años.

2. Se consideran lesiones graves las que ponen en peligro inminente la vida de la víctima, o dejan deformidad, incapacidad o cualquier otra secuela anatómica, fisiológica o síquica.

3. Para adecuar la sanción, el tribunal tiene en cuenta, especialmente, el grado en que la intención del culpable coincide con la naturaleza y entidad de las lesiones causadas.

Artículo 273: El que ciegue, castre o inutilice para la procreación a otro, incurre en sanción de privación de libertad de cinco a doce años.

Artículo 274: El que cause lesiones corporales o dañe la salud a otro que, aun cuando no ponen en peligro la vida de la víctima, ni le dejan las secuelas señaladas en los artículos 272 y 273, requieren para su curación tratamiento médico, incurre en sanción de privación de libertad de tres meses a un año o multa de cien a trescientas cuotas o ambas. 
274, según sea el caso, en relación al 9.3 de esa propia ley. Solución que no resulta forzada porque el término imprudencia alcanza un sentido genérico que abarca todos los matices y expresiones de la acción delictiva no intencional: negligencia, impericia, inobservancia de los reglamentos y la imprudencia propiamente dicha. También han de acogerse los conceptos y procedimientos establecidos en disposiciones complementarias a cuyo análisis se dedica el siguiente epígrafe.

\section{LA RESPONSABILIDAD PENAL POR MALA PRAXIS MÉDICA EN CUBA}

En Cuba, a la par que se garantiza el derecho a la salud, también se asegura protección legal a la práctica médica, en función de mantener el necesario equilibrio de la relación médico-paciente. Llevar un médico ante los tribunales y exigirle responsabilidad penal no es sencillo ni existe espacio para la ligereza. Se debe ser muy cuidadoso al evaluar la responsabilidad médica a fin de evitar lacerar injustamente el prestigio de instituciones asistenciales en general y del médico en particular. Y junto a ello, evitar la desconfianza de los destinatarios de tan imprescindibles servicios. Esto en modo alguno significa generar impunidad, pues en los casos en que por mala praxis ocasionen lesiones o la muerte de una persona, indudablemente los responsables deben ser denunciados, procesados y sancionados con la severidad que amerite.

Si bien en el Código Penal cubano no existe una figura especial para la subsunción del actuar imprudente del médico o personal auxiliar que cause una lesión o la muerte al paciente durante el ejercicio profesional, no ocurre lo mismo en relación al procedimiento. En este ámbito, aunque adolecen de dificultades, existen pronunciamientos específicos para la tramitación de estos procesos penales.

La Resolución No. 99 de 2008 del Ministerio de Salud Pública de Cuba es la norma que en la actualidad establece la metodología para la evaluación de la responsabilidad penal médica. Esta normativa tiene como precedentes y fundamentos legales: el Acuerdo Conjunto del Ministerio del Interior, el Tribunal Supremo Popular, la Fiscalía General de la República y el propio Ministerio de Salud Pública, del 3 de mayo de 1983; la Instrucción No. 110 del 9 de julio de 1983 del Tribunal Supremo Popular; la Ley 41 de Salud Pública del 13 de julio de 1983 y la Ley de Procedimiento Penal del 13 de agosto de 1977.

De conformidad con el Acuerdo Conjunto de mayo de 1983, ante la formulación de una denuncia por mala praxis médica, el instructor penal al proceder a la apertura del expediente de fase preparatoria está en la obligación de solicitar informe o dictamen pericial al director provincial de Salud Pública. Como parte de las acciones de instrucción, a tenor de lo dispuesto en la Instrucción No. 110 de 1983 y la propia Resolución 99, también tendrá que proceder a la verificación del dicho del acusado, reunir una suficiente información testifical con el personal del centro asistencial donde el hecho se haya producido, los familiares de las víctimas y cualquier otra persona que pueda aportar información útil a la investigación. Del mismo 
modo le corresponde obtener, según sea el caso, el resultado de la necropsia o el dictamen de sanidad de lesiones. También otros documentos médico-legales tales como la historia clínica, certificados médicos y los partes de estado, así como un informe circunstanciado sobre los hechos efectuado por el director del centro asistencial donde estos se produjeron. Cada una de las referidas acciones de instrucción se realizará con el debido cumplimiento de las garantías procesales establecidas en la Ley de Procedimiento Penal y se documentará en el expediente de fase preparatoria, así como en la solicitud de peritaje.

La comisión encargada de emitir el dictamen pericial se designará por el Director provincial de Salud mediante resolución. Contará con un número impar de miembros que no podrá ser menor de cinco ni exceder de nueve. Todos pertenecerán al Ministerio de Salud Pública y deberán estar vinculados preferentemente a la especialidad de Medicina Legal, poseer conocimientos de esta especialidad o la suficiente capacidad científica y técnica que les permitan asumir las funciones de la comisión.

En el RESUELVO PRIMERO de la Resolución 99 se aprueba la metodología para la evaluación de la responsabilidad penal médica, a través de la que se establecen los requisitos para la constitución y funcionamiento de la Comisión Médica, creada a los efectos de determinar si ha existido responsabilidad penal de médicos y personal auxiliar que haya intervenido en la atención al paciente lesionado o fallecido. Sin embargo, en su propio anexo se especifica que el objetivo de trabajo de la comisión consiste en valorar y emitir dictamen sobre las violaciones de las reglas del arte médico en la asistencia brindada a un paciente que pudieran constituir actos de responsabilidad médica. Esto en la práctica pudiera ocasionar cierta confusión en el sentido de cuál es la cuestión a resolver por la comisión: si evaluar la responsabilidad penal médica o dictaminar la existencia de violación del arte médico. Ello, porque, a pesar de parecer irrelevante, la primera solo puede ser competencia de los jueces y de atribuírsela a la comisión significaría una invasión de la función judicial.

No obstante, la solución de esta contradicción pudiera resolverse al revisar las exigencias para la elaboración de los seis epígrafes que deben conformar el informe pericial emitido por la comisión. De su estudio se advierte que no se exige declarar en el resultado del peritaje la existencia de responsabilidad penal médica, función exclusiva de los jueces, sino si existe violación de las reglas del arte médico y nexo causal con el daño ocurrido; lo que ilustramos a partir del resumen del contenido de cada uno de los epígrafes:

1. En el encabezamiento se declarará el número de la resolución mediante la cual se crea la comisión, la autoridad solicitante, número del expediente, delito por el que se acusa (lesión u homicidio), generales de la víctima y la fecha en que ocurrieron los hechos.

2. Antecedentes del hecho o información previa al trabajo de la comisión, precisando lo que le interesa que se investigue. 
3. Procederes realizados donde se expongan claramente las acciones que se emprendan.

4. Conocimiento obtenido como resultado de los procederes realizados.

5. En las consideraciones se expone un análisis detallado de la información existente y el modo en que esta se relaciona con la investigación, dejando claro si existe o no nexo causal entre la conducta del inculpado y el daño provocado.

6. Por último, las conclusiones deben responder a la solicitud, significándose si se presentaron elementos constitutivos de violaciones de las reglas del arte médico.

En otro orden, se advierte que entre las funciones del presidente de la comisión está la de rechazar las solicitudes improcedentes, sin que se defina en este instrumento legal cuáles son las causales por las que pueden ser rechazadas. También en la Instrucción 110 de 1983 se establece como uno de los requisitos para que proceda la apertura del juicio oral, la necesidad de que unido al expediente de fase preparatoria conste el informe pericial expedido por la Comisión Médica designada por el director provincial de Salud Pública. Por ello, coincidimos con Arrúe y Azaharez cuando sostienen "(...) que esta concepción puede traer consigo dificultades en el orden procesal y vulnerar principios ya consagrados para el derecho penal (...)"; ${ }^{18}$ toda vez que esta exigencia como requisito previo de admisión de las conclusiones acusatorias y la apertura a juicio oral se traduce en coartación al ejercicio de la acción penal que por mandato constitucional corresponde a la Fiscalía. ${ }^{19}$ Esto, porque resulta evidente que no habrá ejercicio pleno o efectivo de la acción penal sin que previamente se cumpla con dicha exigencia. Lo que al mismo tiempo significa, al decir de estos autores, una ruptura de “(...) la sistemática jurídica seguida en nuestro país para la persecución penal y para establecer la justicia en este orden" ${ }^{20}$ Por tanto, no debía considerarse el dictamen de la comisión como requisito previo y condicionante del proceso penal, sino como prueba pericial que se anexa a las actuaciones conforme acontece para el resto de los delitos y procesos.

En esta dirección, estos autores también sostienen que conforme se advierte del sentido de la Resolución 99 y se constata en la práctica judicial que de su aplicación deriva, la responsabilidad penal del médico o personal auxiliar ya queda fijada antes del juicio oral por la comisión médica. Su dictamen viene a fungir como una suerte de prueba reina o tasada que vulnera principios del debido proceso, como la presunción de inocencia, igualdad, contradicción y la libre valoración de la prueba, imperantes en nuestro esquema procesal. Si cuando

18 Rafael Arrue Caraballo y Germán Azaharez Leal, "Del error médico a la responsabilidad penal, cuestión esencial del tema probado. Una mirada crítica al procedimiento establecido en Cuba”, en Abogacía y derecho: gestión de conflictos jurídicos. Parte.1, Derecho y litigios penales, ed. por Ariel Mantecón Ramos (La Habana: ONBC, 2012), 58.

19 Cf. Artículo 127 de la Constitución de la República de Cuba.

20 Rafael Arrue Caraballo y Germán Azaharez Leal, "Del error médico a la responsabilidad penal, cuestión esencial del tema probado. Una mirada crítica al procedimiento establecido en Cuba”..., 58. 
la comisión elabora el dictamen el fiscal ha considerado suficiente ese criterio para imputar responsabilidad penal, queda poco que hacer en materia de actividad probatoria. La actividad que en este orden "(...) pudiera desplegar el abogado de la defensa queda menguada, pues tendría que vencer un criterio de suficiencia, de lo que es necesario, establecido a priori por exigencia del procedimiento establecido en este cuerpo legal". ${ }^{21}$

A lo anterior se adiciona que, según el Acuerdo Conjunto de 1983 referenciado en uno de los por cuantos de la Resolución 99, en caso de que el informe de la Comisión Provincial de Salud Pública no fuera suficiente para determinar la responsabilidad penal del o de los acusados, el instructor, el fiscal o el tribunal según el estado en que se encuentre el proceso, solicitarán al ministro de Salud Pública la designación de una comisión de la más alta calificación técnica, que determine sobre la actuación de los profesionales acusados. Sin embargo, esto además de reafirmar las reflexiones realizadas, adolece de un desarrollo normativo adecuado. Primero, porque no se explicitan los requerimientos a considerar para la determinación de ese nivel de calificación al que se refiere. También porque no queda definido en la norma el término que tendría esta para constituirse ni para realizar su dictamen, siendo una de las causas por las que en la práctica demoran estos procesos. Asimismo, ocurre que en ocasiones el ministro de Salud Pública ha indicado que sea la propia Comisión Médica Provincial la que vuelva a constituirse a tales efectos, decisión que contradice el sentido de la norma.

Para conocer la opinión de médicos y profesionales del derecho sobre la responsabilidad penal médica por mala praxis y la metodología para su evaluación establecida con la Resolución 99, se encuestaron 25 juristas que ejercen la materia penal: cinco jueces, diez fiscales y diez abogados. Los galenos encuestados fueron 20, de ellos cinco especialistas en medicina legal. Todos con más de diez años de experiencia en el ejercicio de la profesión.

El 67,1 \% refiere que durante el ejercicio de su profesión ha conocido de procesos penales seguidos por delitos de lesiones u homicidio por imprudencia médica. Ello es consecuente con que el 78,8 \% aprecia que en los últimos años los procesos seguidos por tales hechos son más perceptibles. Y, en consecuencia, 89,7 \% considera necesario el perfeccionamiento de la actual regulación de la responsabilidad penal médica por delitos de lesiones y homicidio cometidos por mala praxis en el ejercicio de la medicina. Pero ante la interrogante de si se precisa incluir un tipo penal específico de mala praxis médica, solo 2,6 \% de los encuestados estuvieron de acuerdo. $\mathrm{Y}$ es que en nuestro orden sustantivo no se han pasado por alto las peculiaridades que despierta la imprudencia médica. Pero tampoco se ha recurrido a la crea-

21 Rafael Arrue Caraballo y Germán Azaharez Leal, "Del error médico a la responsabilidad penal, cuestión esencial del tema probado. Una mirada crítica al procedimiento establecido en Cuba”..., 61. 
ción de cláusulas o figuras especiales que representen una reacción más flexible ${ }^{22}$ o enérgica, ${ }^{23}$ frente a la imprudencia profesional médica que frente a aquella de quien no ostenta esta condición. La posición del legislador ha sido la de considerar en estos casos, conforme a las reglas generales de la imprudencia, aquellas en las que pueda incurrir el salubrista con relevancia en esta sede. Por tanto, no debe interpretarse que estos profesionales merecen mayor condescendencia ni un trato más severo, y solo a los tribunales corresponde la valoración, en cada caso, de la gravedad de la actuación imprudente. ${ }^{24}$

A través de la encuesta también fue posible sistematizar que entre los principales problemas que hoy existen en torno a la evaluación de responsabilidad penal médica por mala praxis se encuentran, conforme a las opiniones ofrecidas:

1. Ignorancia de deberes y derechos de los pacientes y médicos.

2. Desconocimiento de los operadores del derecho de la Resolución 99 de 2008.

3. La metodología establecida para la evaluación de la responsabilidad penal médica se circunscribe fundamentalmente a la constitución y funcionamiento de una comisión médica; a los efectos de que sea esta la responsable de evaluar la responsabilidad penal en la que pueda incurrir uno de sus homólogos.

4. La evaluación de la responsabilidad penal no debe quedar en manos de otros profesionales diferentes a los operadores del derecho, aunque en dependencia de la ciencia en que se incursione (en este caso la medicina) sea necesario auxiliarse de especialistas de esa rama del conocimiento.

5. La Comisión Médica no está conformada de forma objetiva. Si su misión es evaluar responsabilidad penal en ella también deben participar juristas.

6. El trabajo de la Comisión Médica debe circunscribirse a aportar a la investigación las violaciones cometidas por los médicos en su proceder y no a determinar si estos son penalmente responsables.

7. Demoras en la elaboración de los dictámenes periciales realizados por la comisión.

8. El resultado del dictamen en ocasiones no deja clara la violación que se produjo ni la relación causal existente entre esta y el daño producido.

22 Así lo hizo el Código Penal austríaco de 1974 en su artículo 88 al establecer que el médico que en el ejercicio de su profesión cause lesiones por imprudencia, quedará exento de pena de no concurrir culpabilidad grave, siempre que no resulte una lesión de la salud ni una incapacidad laboral superior a 14 días.

23 Es el caso del Código Penal español, Ley Orgánica No. 10-1995, de 23 de noviembre, conforme lo sugieren las reglas, cláusulas o disposiciones especiales que incorpora con un sentido agravatorio, por ejemplo, en los tipos penales de Homicidio (art.142.3), Lesiones (art. 152.3), Aborto (art. 146.2), entre otros. Así, en caso de homicidio establece con carácter preceptivo la sanción de inhabilitación especial para el ejercicio de profesión, oficio o cargo por un período de tres a seis años.

24 María del Carmen Gómez Rivero, La responsabilidad penal del médico (Valencia: Tirant lo Blanch, 2003), 328-329. 
9. Falta de claridad, objetividad y demoras en la constitución de una comisión de más alta calificación o jerarquía para confrontar el dictamen emitido por la comisión provincial, en caso de inconformidad de alguno de los actuantes en el proceso.

Para una mejor evaluación de los casos de responsabilidad penal médica por mala praxis los encuestados consideran que se debe:

1. Analizar la Resolución 99 de 2008 en los diferentes centros asistenciales del país, con el objetivo de elevar la prevención de la ocurrencia de casos de mala praxis médica.

2. Instituir que, ante quejas formuladas en cualquier institución de salud, por parte de los pacientes o sus familiares a causa de lesiones o fallecimientos, ocurridos supuestamente como consecuencia de un mal proceder médico, los directivos de estas deberán orientarlo sobre cómo proceder y a su vez dar parte a las autoridades competentes para conocer el caso, quienes serán los únicos facultados para discernir si procede o no la denuncia y posterior apertura del expediente de fase preparatoria.

3. Asegurar la agilidad en la conformación de las comisiones y la elaboración de los dictámenes.

4. Garantizar la inviolabilidad en relación a la no inclusión en la Comisión Médica, de personal asistencial del centro donde se produjeron los hechos.

5. Garantizar que ante desacuerdo con el dictamen pericial emitido por la Comisión Médica el caso sea evaluado por una comisión diferente, con preferencia una de más alta calificación técnica y jerárquica.

6. Incluir en la integración de la Comisión Médica, como mínimo a un profesional del Derecho.

7. Derogar la Resolución 99 y diseñar una nueva disposición en la que se solventen las deficiencias que ella presenta e integre lo pautado en el resto de las disposiciones que regulan el procedimiento para la evaluación de responsabilidad penal médica, donde se armonicen cuestiones teóricas, sustantivas y procesales.

En resumen, con independencia de las motivaciones que fundamentan su adopción, la Resolución 99 no resuelve las problemáticas que en la actualidad generan los procesos seguidos contra médicos y personal auxiliar que hayan intervenido en la atención al paciente que resultó lesionado o fallecido. A contrario sensu, por la complejidad que revisten estos procesos, así como las omisiones y contradicciones de las que adolece esta normativa, genera otras confusiones e insatisfacciones. Ello requiere en los momentos actuales de propuestas que posibiliten perfeccionarla para asegurar la efectiva evaluación de la responsabilidad penal médica por mala praxis, así como garantizar con mayor efectividad los derechos en juego: la vida y la salud de las personas por un lado, y el prestigio y reconocimiento que el ejercicio de una actividad como la medicina demanda. 


\section{BASES PARA LA DETERMINACIÓN DE LA RESPONSABILIDAD PENAL POR MALA PRAXIS MÉDICA}

El recorrido teórico-doctrinal realizado por los senderos de la mala praxis médica como generadora de responsabilidad penal por los resultados de daño a la vida y salud de las personas, así como el criterio de médicos y abogados vinculados al tema, no solo permitió la identificación de las deficiencias de la concepción jurídica en Cuba para la evaluación de la responsabilidad penal por mala praxis; también posibilitó la formulación de propuestas para su correcta configuración en el ordenamiento jurídico.

Para ello se diseñaron un conjunto de bases como sustento primordial de lege ferenda en una posterior perfección legislativa y su apreciación por parte de los tribunales en su labor de interpretación y aplicación del derecho. Estas vendrían a constituirse en una especie de herramienta teórico-doctrinal y metodológica para que juristas y profesionales de la salud se encuentren en mejores condiciones de enfrentar casos donde se debata la posible existencia de responsabilidad penal médica por mala praxis.

Para la conformación de las bases se adoptaron un conjunto de criterios teórico-doctrinales y de orientación metodológica. El criterio metodológico estuvo condicionado primordialmente por los estudios nacionales; lo abstracto de los contenidos relacionados con la configuración de la responsabilidad penal médica en la ley sustantiva penal y las disposiciones de las que hoy se auxilian los operadores del derecho para la evaluación de la institución jurídica objeto de investigación. Ello exigió observar los siguientes pasos por cada uno de los criterios:

Teóricos-doctrinales:

1. Estudio de las teorías capaces de explicar cuándo se configura la mala praxis médica penalmente relevante.

2. Análisis de las diferentes formas de manifestarse la mala praxis médica.

3. Creación de un esquema conceptual a aplicar al problema de la investigación.

Metodológicos:

4. Observación de casos concretos a través de la revisión de causas del Tribunal Provincial Popular de Guantánamo.

5. Identificación de los aciertos y desaciertos de las disposiciones que establecen el procedimiento para la evaluación de responsabilidad penal médica.

6. Recopilación de criterios de profesionales vinculados al tema, a partir de la aplicación de encuestas. 
Las bases se estructuraron en dos grupos atendiendo a sus características:

PRIMER GRUPO: Bases que integran el marco conceptual-teórico para la evaluación de la responsabilidad penal médica por mala praxis (conceptos claves).

Acto médico: Está conformado por todas las conductas desplegadas por un médico dentro del marco del desarrollo del ejercicio de su profesión, lo cual incluye toda la relación médico-paciente desde las etapas preliminares de conocimiento y análisis, hasta las etapas posteriores al tratamiento como la evolución y rehabilitación del paciente. Presupone una obligación legal, la cual se origina de la interacción médico-paciente, ya que en ese momento nace la relación jurídico-médica a partir del reconocimiento de los derechos y obligaciones de ambos. Lo distinguen cuatro características: 1) la profesionalidad, 2) su ejecución conforme a la Lex Artis Ad Hoc, 3) la licitud y 4) el objetivo de curar o rehabilitar al enfermo.

Relación médico-paciente: Cuando una persona se siente enferma y concurre a la consulta clínica, comienza a tejerse un complejo entramado de relación interpersonal en la que uno y otro, paciente y médico, se encuentran igualmente implicados. Así, por la importancia de los bienes en riesgo ( $v . g r$., la vida y salud de las personas), dicha relación alcanza la tutela del derecho configurándose la relación jurídica médico-paciente. En Cuba, la relación médico-paciente se establece a partir de un vínculo de facto que se genera en la atención médica, tanto en los servicios de urgencia como electivos. Por tanto, son sujetos primarios de dicho vínculo el paciente y el profesional encargado de su atención.

Peligrosidad social del acto médico: Cualidad objetiva del acto médico de significar un peligro real o potencial a la vida o integridad de los pacientes.

Resultados adversos: Son aquellos daños que se producen a la vida o la salud del paciente derivados de la realización del acto médico y que dependiendo de sus características o causa pueden generar responsabilidad jurídica.

Mala praxis médica: Es la acción de dañar total o parcialmente, temporal o de manera permanente, la salud humana en el contexto de la relación médico-paciente. Obedece a la actuación por imprudencia, negligencia, impericia o inobservancia de los reglamentos y deberes exigidos a los salubristas durante la realización de cualquier acto médico. En estos casos, el daño producido es previsible, pero no se previó o habiéndose previsto el facultativo confió en que podía evitarlo sin que lo lograra. Se trata de un daño provocado por culpa al violar las reglas del arte médico y, por tanto, evitable con una buena práctica profesional.

Arte médico (lex artis): Conjunto de normas y procedimientos adoptados en diversos documentos, guías de buenas prácticas, manuales y protocolos que deben observar los médicos en el desempeño profesional. A partir de su evaluación se juzga si el acto médico desarrollado 
por el facultativo es o no correcto o se ajusta o no a lo que debe hacerse. Es decir, se intenta calificar si la actuación del profesional cuestionado se ajusta al concepto de excelencia en el momento en que se juzga. Pero el cumplimiento de estas reglas debe valorarse a partir del concreto acto médico ejecutado por el profesional de la medicina. En consecuencia, han de considerarse las especiales características de su autor, de la profesión, la complejidad y trascendencia vital del acto, así como la influencia de factores endógenos para calificarlo de conforme o no con la técnica normal requerida. No es por ello de extrañar que se haya llegado a afirmar que en el ámbito médico se hace realidad la regla "cada acto una ley", hasta el punto de que "es el mismo acto que genera, por una especie de mecanismo de autorregulación, su propia ley, con la que indefectiblemente, habrá de enjuiciarlo". ${ }^{25}$

Imprudencia: Consiste en una conducta positiva, al realizar un hecho que había que abstenerse de hacer por la posibilidad de producir un daño o peligro, o bien que se ejecuta un hecho de modo inadecuado que resulta peligroso para terceros. Es aplicable a los médicos cuando provocan un mal a consecuencia de su actuar precipitado y sin el cuidado que la ciencia y la experiencia médica enseñan que se debe tener en cuenta al tratar a un enfermo, existiendo un incumplimiento del deber de atención y cuidado. ${ }^{26}$

Negligencia: Es una especie de conducta omisa que se contrapone a las normas que exigen una determinada actuación solicitada, atenta y sagaz. Es utilizada para describir el descuido y la desatención, en no prever lo previsible, resultado de lo cual se perjudica la salud del paciente. ${ }^{27}$

Impericia: Está genéricamente determinada por la insuficiencia de conocimientos para la atención del caso, que se presumen y se consideran adquiridos por la obtención del título profesional y el ejercicio de la profesión. Puede ser de origen, de olvido o de práctica. Solo será relevante jurídica y penalmente cuando es grosera y el sujeto podía evitarla tomando ciertas precauciones. Se dice que la impericia es grosera cuando el médico, a pesar de estar capacitado para el desempeño de su profesión, emplea deficientemente o no emplea los conocimientos científicos y técnicos requeridos en el proceder que ejecuta y causa la muerte o lesión del paciente, existiendo un nexo causal con la acción u omisión médica. No se exigen conocimientos extraordinarios o fuera de los normales, sino los que la sana lógica indique que debe poseer un profesional en esta materia, puesto que la pericia que se exige es la pericia media, la pericia normal. ${ }^{28}$

25 Martínez-Calcerrada, como se citó en María del Carmen Gómez Rivero, La responsabilidad penal del médico (Valencia: Tirant lo Blanch, 2003), 338.

26 Véase Anexo a la Resolución Ministerial 99 de 2008.

27 Ibid.

28 Ibid. 
La inobservancia de los reglamentos: Esta se manifiesta cuando el agente no cumple las medidas que se le imponen con carácter obligatorio en los mismos; ya que, en el ejercicio de la profesión médica, el facultativo viene obligado al estricto cumplimiento de los preceptos contenidos tanto en los reglamentos de carácter general como específicos, pudiendo derivarse de su inobservancia, una responsabilidad no solo en el orden laboral o administrativo sino penal. $^{29}$

Responsabilidad penal médica: Es la obligación que tiene toda persona que ejerce cualquier rama de la medicina de sufrir las consecuencias legalmente instituidas (las sanciones o penas), por la perpetración de un hecho socialmente peligroso y antijurídico también previsto en la ley (los delitos).

SEGUNDO GRUPO: Bases metodológicas a tener en cuenta para la evaluación de la responsabilidad penal médica por mala praxis.

A. Bases de orientación metodológica constituidas por los elementos configuradores de la responsabilidad penal médica por mala praxis

1. Existencia de una conducta médica (acción u omisión) que se produce en el marco de la relación médico-paciente y cuya concreción se alcanza en el acto médico.

2. La ejecución del acto médico debe significar una violación de las reglas del arte médico, el ordenamiento jurídico en general y penal de manera particular, es decir, debe considerarse la antijuridicidad de la conducta médica.

3. Como resultado del acto médico debe producirse una lesión a la vida o la salud del paciente (daño).

4. Debe existir una directa relación entre la falta cometida por el médico y el daño o perjuicio antijurídico ocasionado (nexo o vínculo causal).

5. El resultado antijurídico le debe ser atribuido al galeno a título de culpa.

6. El resultado de daño debe alcanzar por su magnitud o peligrosidad social, los predios del derecho penal.

B. Bases para justipreciar la responsabilidad penal por mala praxis médica

1. Las circunstancias concurrentes en el caso concreto: urgencia de la intervención, su grado de complejidad, circunstancias de lugar y tiempo en que se realiza el acto médico y los medios disponibles al alcance del profesional.

29 Ibid. 
2. Relevancia de los bienes afectados en relación con las posibilidades de éxito del tratamiento.

3. El grado de previsibilidad del riesgo.

4. Los conocimientos y capacidades especiales del autor (concepción individualizadora del injusto). Grado de especialización que exige el acto médico en relación con su cualificación.

Pero debe precisarse que todos estos aspectos en el ámbito médico deben conjugarse con la relatividad misma que caracteriza la ciencia médica. Sobre esta base se ha de justipreciar la medida del deber de cuidado exigido al galeno y definir, por tanto, la imprudencia en relación a los caracteres que reviste la acción concreta. Asimismo, la relatividad en la forma de conjugar todos esos aspectos no se agota en la atención a los múltiples indicadores que pueden delatar una acción como imprudente. La ponderación de la diligencia exigible a la conducta médica ha de evaluarse adicionalmente por la fase del tratamiento sobre la que recaiga. Así, por ejemplo, los actos diagnósticos son de los más polémicos en clave de determinación de la responsabilidad médica cuando se comete un yerro en su realización. Bajo esta postura, la doctrina y jurisprudencia extranjera suele inclinarse hacia la necesidad de admitir un margen razonable de equivocación en estos tipos de actos médicos que hacen que el diagnóstico desacertado o erróneo que no califique como burdo, escape con facilidad a la consideración del acto médico como imprudente. ${ }^{30}$

Hasta aquí se han tratado de sistematizar las coordenadas desde las que puede evaluarse la responsabilidad penal médica por mala praxis penalmente relevante. La mesura y la reflexión han marcado los senderos de este iter, y una vez desarrollada la perspectiva teórica y valorativa que sostenemos para lograr los resultados, solo nos resta afirmar, al lado de uno los principales cultores del derecho penal de estos tiempos: "El derecho penal tiene que mantener la vinculación con el cambio social: tiene que estar preparado para dar respuesta a las preguntas de hoy (...). Tiene que seguir evolucionando en contacto con su realidad". ${ }^{31}$

\section{CONSIDERACIONES FINALES}

La mala praxis médica genera resultados adversos, pero no todo resultado adverso es producto de una mala praxis. Solo esta, dentro del catálogo de aquellos, genera responsabilidad penal a título de culpa por violación del arte médico si se configuran los restantes rasgos que caracterizan una conducta como delictiva (tipicidad, antijuridicidad, culpabilidad, punibi-

30 María del Carmen Gómez Rivero, La responsabilidad penal del médico (Valencia: Tirant lo Blanch, 2003), 338-339.

31 W. Hassemer, "La ciencia jurídico-penal en la República Federal Alemana", Anuario de Derecho Penal y Ciencias Penales, tomo XLVI, fascículo I (enero - abril 1993): 79. 
lidad). Se produce en el marco de la relación médico-paciente resultado de la ejecución de un acto médico indebido por imprudencia, impericia, negligencia y la inobservancia de los reglamentos, que implica la afectación de bienes jurídicos tutelados por el derecho, como la vida y salud de las personas.

En el ordenamiento jurídico-cubano, aunque se establecen figuras de delito que prevén como sujeto activo al médico, no existe un tipo penal independiente para la regulación de mala praxis médica, lo que no significa que no encuentre en sus normas una respuesta penológica. Las mayores deficiencias se identifican en el ámbito procesal, en el que las iniciativas normativas adolecen de omisiones y contradicciones que inciden en la consecución de un expedito y debido proceso para la evaluación de la responsabilidad penal en que puedan incurrir los facultativos.

El recorrido teórico-doctrinal y práctico realizado posibilitó la formulación de bases para la evaluación de la mala praxis médica en aras del perfeccionamiento del ordenamiento jurídico cubano. Estas revisten importancia en el proceso de interpretación y aplicación de las disposiciones existentes. También pueden considerarse como presupuestos de lege ferenda a valorar por el legislador al momento de la perfección normativa, las que se agrupan de la siguiente forma:

Primer grupo: Bases que integran el marco conceptual-teórico para la evaluación de la responsabilidad penal médica por mala praxis.

Segundo grupo: Bases metodológicas a tener en cuenta para la evaluación de la responsabilidad penal médica por mala praxis.

\section{REFERENCIAS}

- Alarcón Borges, Ramón Yordanis. "Las normas penales en blanco en el ordenamiento jurídico penal cubano. Tesis presentada en opción al grado científico de Dr. en Ciencias Jurídicas. Universidad de Oriente, Santiago de Cuba, 2011.

- Arrue Caraballo, Rafael y Germán Azaharez Leal. "Del error médico a la responsabilidad penal, cuestión esencial del tema probado. Una mirada crítica al procedimiento establecido en Cuba". En Abogacia y derecho: gestión de conflictos jurídicos. Parte 1, Derecho y litigios penales, ed. por Ariel Mantecón Ramos, 41-63. La Habana: ONBC, 2012.

- Baquero Vernier, Ulises. Derecho penal general. Santiago de Cuba: ENSPES, 1984. 
- Berro Rovira, Guido. "La relación médico-paciente (RMP) y su actual encuadre legal”. Revista Biomedicina (2009): 16-23. Acceso el 8 de agosto de 2017 desdehttps:/www.google. com.cu/url?sa=t\&rct=j\&q=\&esrc=s\&source=web\&cd=2\&ved=0ahUKEwjs2Mzvl8jVAhWJbiYKHYdtBJMQFggvMAE\&url=https\%3A\%2F\%2Fwww.researchgate.net\%2Fpublication\%2F45523004_La_relacion_medico-paciente_RMP_y_su_actual_encuadre_legal\&usg=AFQjCNGO-Hx0bYAFidj1 rwkp48sNrUORWQ

- Fernández Bulté, Julio. Teoría del Estado y del derecho. Teoría del derecho. La Habana: Editorial Félix Varela, 2011.

- Gómez Rivero, María del Carmen. La responsabilidad penal del médico. Valencia: Tirant lo Blanch, 2003.

- Hassemer, W. "La ciencia jurídico-penal en la República Federal Alemana”. Anuario de Derecho Penal y Ciencias Penales, tomo XLVI, fascículo I (enero - abril 1993).

- Medina Cuenca, Arnal. “Comentarios a la Ley No. 62 de 29 de septiembre de 1987: Código Penal”. En Derecho penal especial. Tomo 3. Colectivos de autores, 55-67. La Habana: Editorial Feliz Varela, 2003.

- Navarro Odio, Carmen. "La responsabilidad jurídica penal del médico en Cuba”. Tesis de Grado. Universidad de Oriente, Santiago de Cuba, 2014.

- Parets Gómez, Jesús. "La responsabilidad penal del médico". Revista Cubana de Derecho 2, (1991): 84-94. Acceso el 16 de enero de 2016. http://vlex.com/vid/responsabilidad-penal-medico-45042501

- Portero Lazcano, Guillermo. "Responsabilidad penal culposa del médico: fundamentos para el establecimiento de la negligencia o impericia". Revista Latinoamericana de Derecho Médico y Medicina Legal 7, 1, (2002): 89-96.

- Sanmartín, Joaquín, traductor. Códigos legales de tradición babilónica. Barcelona: Trotta, 1999.

- Tapia, T. E y V. X. Tapia. "La mala praxis médica, encuadre y consecuencias en el derecho penal y derecho civil”. Tesis de grado, Universidad Técnica de Cotopaxi en convenio con la Universidad de la Cuenca del Plata, Corrientes, Argentina, 2010.

\section{FUENTES NORMATIVAS}

- Acuerdo Conjunto del Ministerio del Interior, el Tribunal Supremo Popular, la Fiscalía General de la República y Ministerio de Salud Pública de la República de Cuba, del 3 de mayo de 1983. 
- Código de Defensa Social. Publicación autorizada por Decreto Presidencial No. 973 de 17 de abril de 1936. Jesús Montero, Editor. La Habana. 1953.

- Decreto-Ley 140, Modificaciones al Código Penal cubano. Gaceta Oficial, Extraordinaria, No. 4, 13 de agosto de 1993.

- Decreto-Ley 150, Modificaciones al Código Penal cubano. Gaceta Oficial, Extraordinaria, No. 6 de 10 de junio de 1994.

- Decreto-Ley 175, Modificaciones al Código Penal cubano. Gaceta Oficial, Extraordinaria, No. 6, 26 de junio de 1997.

- Instrucción No.110 del Consejo de Gobierno del Tribunal Supremo Popular de la República de Cuba del 9 de julio de 1983.

- Ley de Procedimiento Penal, "Ley No. 5 de 13 de agosto de 1997”.

- Ley No. 21 “Código Penal”, 1979.

- Ley No. 41 "Ley de Salud Pública de la República de Cuba”, de 13 de julio de 1983

- Ley No. 62 "Código Penal de la República de Cuba", 1987, que entró en vigor el 30 de abril de 1988.

- Ley No. 87, Modificaciones al Código Penal de la República de Cuba. Gaceta Oficial, No. 1 de 15 de marzo de 1999.

- Resolución No. 99 del Ministerio de Salud Pública de la República de Cuba, "Metodología para la evaluación de la responsabilidad penal médica", del 7 abril de 2008.

Recibido: $1 / 10 / 2017$

Aprobado: 23/03/2018 